\title{
AEROMAGNETIC MAP OF THE HAMPDEN QUADRANGLE HAMPDEN COUNTY, MASSACHUSETTS, AND TOLLAND COUNTY, CONNECTICUT
}

\author{
GEOPHYSICAL INVESTIGATIONS \\ MAP GP-629
}

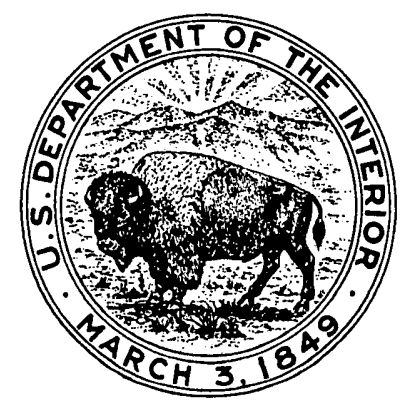

PUBLISHED BY THE U.S. GEOLOGICAL SURVEY WASHINGTON, D. C. 